University of Nebraska - Lincoln

DigitalCommons@University of Nebraska - Lincoln

Agronomy \& Horticulture -- Faculty Publications

Agronomy and Horticulture Department

2005

Estimating Surface Wetness on Plants

R.D. MAGAREY

New York State Agricultural Experiment Station

R.C. SEEM

New York State Agricultural Experiment Station

A. WEISS

University of Nebraska-Lincoln, aweiss1@unl.edu

T. GILLESPIE

University of Guelph

L. HUBER

Institut National de la Recherche Agronomique

Follow this and additional works at: https://digitalcommons.unl.edu/agronomyfacpub

MAGAREY, R.D.; SEEM, R.C.; WEISS, A.; GILLESPIE, T.; and HUBER, L., "Estimating Surface Wetness on Plants" (2005). Agronomy \& Horticulture -- Faculty Publications. 696.

https://digitalcommons.unl.edu/agronomyfacpub/696

This Article is brought to you for free and open access by the Agronomy and Horticulture Department at DigitalCommons@University of Nebraska - Lincoln. It has been accepted for inclusion in Agronomy \& Horticulture -Faculty Publications by an authorized administrator of DigitalCommons@University of Nebraska - Lincoln. 


\title{
Estimating Surface Wetness on Plants
}

\author{
R.D. MAGAREY AND R.C. SEEM \\ New York State Agricultural Experiment Station \\ Geneva, New York
}

\author{
A. WEISS \\ University of Nebraska \\ Lincoln, Nebraska \\ T. GILLESPIE \\ University of Guelph \\ Guelph, Canada
}

L. HUBER

Institut National de la Recherche Agronomique

Thiverval-Grignon, France

Plant surface (leaf, stem, petiole, etc) wetness or leaf wetness is an important agricultural weather variable for the prediction of plant diseases (Yarwood, 1978). The estimation of surface wetness has received considerable attention from a diverse group of scientists but unfortunately, no standard for measuring surface wetness has been widely accepted. Since surface wetness is not a true meteorological variable, as is temperature or precipitation, its measurement has not been routinely made as part of a general observation program by most national meteorological agencies. The main problem of not observing surface wetness on a routine basis has been the lack of agreement about a standard sensor design and protocol for the use of sensors. In addition, most sensors measure surface wetness indirectly and have different physical properties. In order for a sensor to represent a particular crop, plant organ, or environment, the sensor should be calibrated with visual observations of surface wetness. Unfortunately, the collection of visual observations is labor intensive and difficult, since there is no universally accepted definition for plant surface wetness.

In this chapter, we will attempt to define surface wetness in physical terms and review methods for determining surface wetness. We also will consider solutions to the lack of surface wetness standardization from both a measurement and simulation perspective. And finally, we will also recommend the most suitable protocols for estimating surface wetness.

Copyright (C2005. American Society of Agronomy, Crop Science Society of America, Soil Science Society of America, 677 S. Segoe Rd., Madison, WI 53711, USA. Micrometeorology in Agricultural Systems, Agronomy Monograph no. 47. 


\section{Causes of Surface Wetness}

Rain, dew, guttation from leaves, or overhead irrigation may all cause surface wetness. Unlike dew, rain occurs across a broad temperature range and splashing raindrops help disperse fungal spores (Royle \& Butler, 1986). Surface wetness periods caused by rain may last for multiple days, whereas dew events are usually nocturnal and morning phenomena in most crops. Rain presents two main problems for surface wetness determination. Rain may be quite spatially variable when it falls from convective activity or in variable topography (Linacre, 1992) and the distribution of water in dense and tall canopies after rain may be uncertain (Sellers \& Lockwood, 1981; Watanabe \& Mizutani, 1996).

Irrigation is an important source of surface wetness when the irrigation is applied by overhead or above the row sprinklers (Lomas, 1991). Other types of irrigation add to soil moisture and increase wetness indirectly by promoting dew. Dew forms on a leaf surface as result of radiative cooling, when the leaf surface temperature drops below the dewpoint temperature of ambient air. It is important to make a distinction between the sources of moisture for surface wetness, from the atmosphere (i.e., dew fall) or from the soil (i.e., dew rise or distillation) (Monteith, 1957). Dew rise is likely to be dominant under calm conditions when the soil is wet. A wet soil surface can increase surface wetness duration by as much as $2 \mathrm{~h}$ (Wilson et al., 1999). Maximum dewfalls may be expected on cloudless nights under low wind speeds, e.g., below $4 \mathrm{~m} \mathrm{~s}^{-1}$ at $10 \mathrm{~m}$ height (Garratt \& Segal, 1988). Measured amounts of maximum dew deposition per night can range from 0.3 to $0.6 \mathrm{~mm}$ and theoretical maximum rates of dew formation are about $0.08 \mathrm{~mm} \mathrm{~h}^{-1}$ (Garratt \& Segal, 1988). Dew deposition over time has been measured and studied accurately on maize (Zea mays L., Jacobs et al., 1994).

Wetness also can be caused by guttation, which consists of water drops produced at hydrathodes, located along the margins of leaves (Hugues \& Brimblecombe, 1994). When the surrounding air is close to saturation, these drops grow as water is supplied to the vascular system. Guttation can make a contribution of a similar magnitude to dew in flooded rice (Oryza sativa L.) fields in the humid tropics (Weihong \& Goudriaan, 1999, 2000). Unfortunately, guttation is not easily measured with existing surface wetness sensors, nor is it included in most surface wetness models.

\section{Distribution of Water on Plant Surfaces}

Moisture on a plant surface may be distributed in drop or film form depending upon the hydrophobicity of the leaf. Surface wetness usually exists as large drops that wet from 6 to $20 \%$ of a plant surface depending on the surface type (Brain \& Butler, 1985; Norman \& Campbell, 1983). This droplet distribution results from leaves generally being hydrophobic, an important adaptation as surface wetness disrupts gas exchange processes (Brewer \& Smith, 1997). Hydrophobicity is related to trichome density (Brewer et al., 1991; Hall et al., 1997): however, surface moisture also may be present as a film covering a high proportion of the surface area in some circumstances. For example, the immature leaves of some species may be relatively hydrophyllic (Hall et al., 1997). In addi- 
tion, during dew events, condensation produces discrete microdrops that only later aggregate to form larger drops.

\section{Definition of Surface Wetness, Surface Wetness Period and Surface Wetness Duration}

Surface wetness is commonly accepted as the visible presence of water on a plant surface (Armstrong et al., 1993; Butt \& McGlinn, 1989; Gillespie \& Kidd, 1978; Hoppmann \& Wittich, 1997; Potratz et al., 1994; Weiss \& Hagan, 1983). Although the term "leaf wetness" is commonly used to describe moisture on leaves in a canopy, it is too specific since wetness also can occur on other plant parts such as stems, flowers, or fruits. Surface wetness is a preferred term since it applies to moisture on all plant parts (Butt \& McGlinn, 1989; Hirst, 1954). It is appropriate to define surface wetness in physical terms as the visible presence of wetness on plant parts. Visual observation is an appropriate definition because it is a non-intrusive measurement and large canopy areas may be observed more rapidly than by other sensing methods; however, for experimental purposes, touch with a sensitive part of the skin (e.g., lips or back of the hand) may be the most suitable method of determining surface wetness when it is not clearly visible. The biological role of microscopic surface wetness is uncertain. Although, films may remain microscopic for periods greater than an hour (Giesler et al., 1996), an extended duration is likely to result in visible wetness in at least some portion of the canopy. Since visual observations are time consuming to collect, an operational definition of surface wetness can be defined as the no-yes response of an electronic or mechanical sensor (Huber \& Gillespie, 1992; Jones, 1986) or a simulation model. Since most sensors provide an indirect measurement of surface wetness it is important that the sensor or model be calibrated against visual observations.

Another attribute of surface wetness is the wetness period. After wetting, moisture will remain visible as a film or drops over a length of time. This length of time of "continuous" wetness is the "wetness period." The wetness period is synonymous with the experimental definition of the water requirement for disease development. In classical plant pathology experiments, inoculated plants are incubated wet for variable periods at different constant temperatures (Rotem, 1988). The observations are analyzed to find a temperature-moisture relationship, which describes pathogen ontogeny, including the onset of infection. In studies where inoculated plants were subjected to alternating wet and dry conditions, the intervening dry periods caused spore mortality and reduced the incidence of infection (Huber \& Gillespie, 1992; Llorente \& Montesinos, 2002). Research has revealed that wetness periods in an experimental setting can be considered random and exhibit multi-modal frequency distributions. In these distributions, the primary mode of wetness periods was at $1 \mathrm{~h}$, and increasingly smaller modes occurred at 12-h intervals owing to diurnal periodicity (Seem et al., 1988). Multi-modal frequency distributions could be helpful in determining the longevity of a wetness period and its impact on disease development.

Surface wetness period should not be confused with surface wetness duration, which is defined here as the sum of wetness periods that occur between dry 
periods. It is important to state the temporal and spatial scales of the original sample when reporting surface wetness duration. For practical applications, hours are the most appropriate time scale since meteorological data are most commonly recorded in hours and the canopy is best spatial scale since treatments are usually applied to a whole canopy rather than individual organs. Using these criteria, a suggested operational definition of the canopy surface wetness duration (CSWD) is surface wetness present for $12 \mathrm{~min}$ or more on $10 \%$ or more of leaves (or other plant parts) in a canopy (Magarey, 1999). The value of CSWD is 1 (yes) or 0 (no) at an hourly sampling frequency. The use of a binary variable to classify hours as either totally wet or totally dry matches with most practical field-scale schemes that use hourly surface wetness as a management tool. Since observations or measurements of surface wetness may be collected at time intervals smaller than an hour, it is necessary to define a time threshold for which an hour is considered wet. The 12-min threshold is arbitrary but conservative, since it is better to overestimate than underestimate surface wetness for plant protection purposes. In contrast, a 30-min threshold may result in a substantial underestimation of wetness. The area threshold of $10 \%$ or more of leaves or plant parts in a canopy minimizes the influence of the larger drops of water that may persist for long periods after the remainder of the canopy has dried.

\section{Importance of Surface Wetness}

Since the 1950s, surface wetness has been used as a variable for the prediction of plant diseases (Huber \& Gillespie 1992). Surface wetness has an important role in the development of many plant pathogens and arthropods. For example, it plays an important role in the dispersal of shoot fly larvae (Atherigona soccata), an important pest of sorghum (Sorghum bicolor (L.) Moench) in India (Nwanze et al., 1996). Surface wetness also may reduce spider mite populations (Holtzer et al., 1988). This is in part due to the greater activity of fungal pathogens of mites under wet conditions. In fungal pathogens, it influences the processes of germination, infection, sporulation and to a lesser extent the time for symptom development (latent period) (Huber \& Gillespie, 1992; Yarwood, 1978). The duration of wetness required for infection is dependent upon temperature. The temperature wetness interaction is studied by inoculating plants with a spore suspension and holding them under controlled conditions of relative humidity and temperature. The equipment used for this purpose varies from enclosed plastic bags to sophisticated incubation chambers with misting systems (Rotem, 1988). There have been $>55$ studies in which the temperature wetness interaction of foliar pathogens has been quantified (Magarey, 2002, unpublished data). The minimum hours of surface wetness required across a range of temperatures can be described by a beta function (Analytis, 1977). The global range of surface wetness requirement for pathogenic development varies from $0.5 \mathrm{~h}$ to $>100 \mathrm{~h}$. Some plant pathogens are extremely dependent upon surface wetness, for example the downy mildews (Peronosporeae), while for other pathogens such as the powdery mildews (Erysiphaceae) surface wetness may have a detrimental influence (Huber \& Gillespie, 1992).

A large number of disease forecast models use surface wetness as an input (Campbell \& Madden, 1990). These models are used to time the application of 
fungicides and provide effective disease management with the potential to reduce the number of total applications. Consequently, the need for surface wetness has been a driving force in the establishment of weather station networks in many agricultural areas. Similarly, surface wetness data derived from simulated observations and site-specific forecasts are used commercially for disease prediction (Russo, 2000).

Surface wetness can have a direct impact on plants. Brewer and Smith (1997) found that plant species growing in open habitats had many adaptations that assisted the plants in shedding water from their surfaces in order to promote leaf gas exchange. These adaptations included higher densities of trichomes and waxier cuticles than species that are commonly found in understorey habitats. Surface wetness also plays a role in the relationship between phytotoxicity and pollution. Wetness enhances the dynamic deposition of air pollutants on the plant surface (Lee \& Wesley, 1989; Schuepp, 1989) due to a possible decrease in cuticular resistance (Burkhardt \& Eiden, 1994). Surface wetness from dew is an important water source for many xerophytic plants (Louw \& Seely, 1982) and impedes the drying of hay and other agricultural products (Tuzet et al., 1993).

\section{DESIGN OF SENSORS AND SIMULATION MODELS}

\section{Sensors}

Many types of instruments have been constructed for the measurement of surface wetness (Weiss 1990), which has contributed to a lack of standardization in measurement and definition of terms, as previously noted. Until the 1970s, mechanical sensors (Hirst, 1954; Lomas \& Shashoua, 1970; Wallin, 1963) were widely used, but they have been largely replaced with electronic types (Schurer \& Van Der Wal, 1972). The U.S. National Weather Service was one of the first organizations to use an etched circuit board that has become one of the most widely used sensor designs (Davis \& Hughes, 1970). Electronic sensors measure surface water deposition by a change in sensor impedance, which is a combination of sensor resistance and capacitance. An AC circuit is used to prevent the undesirable deposition of electrolytes from the water onto the sensor. A dry surface has infinite impedance while a wet surface has relatively low impedance. A sensor consists of a series of adjacent, independent elements, ranging in size from thin wires to grid networks etched on a printed circuit board (Huband \& Butler, 1984; Weiss \& Lukens, 1981). When water touches two adjacent elements a circuit is completed and the impedance changes. Although grid elements are commonly spaced at $1 \mathrm{~mm}$ (Gillespie \& Kidd, 1978) a recent study in a greenhouse found that $0.25 \mathrm{~mm}$ spacings had a greater accuracy (Wei et al., 1995). It is unclear if such narrow spacings would be practical in an outdoor environment.

Following Häckel (1980), Weiss et al. (1988) investigated the direct measurement of surface wetness by placing grid elements on a leaf surface. These sensors have not gained widespread adoption, probably because they must be custom built and daily checks are required to ensure that they have good contact with the leaf surface (Sutton et al., 1984). Another sensor design consists of a network of wires covered by a piece of cotton cloth. This sensor often performed better than 
an etched circuit board sensor (Weiss \& Hagen, 1983; Weiss \& Lukens, 1981) but not as well in heavy dews (Armstrong et al., 1993). The durability of the cloth sensor under heavy rain also can be a problem.

Another important consideration in sensor design is that the size and shape of the surface wetness sensor be similar to that of the plant organ being studied (Sutton et al., 1984). In onions (Allium sp.), a cylindrical shaped sensor was effective (Gillespie \& Duan, 1987), while Huband and Butler (1984) used a flexible sensor to simulate the movement of wheat (Triticum aestivum L.) leaves in the wind. A cylindrical sensor was found more effective than a flat plate sensor when used outside an apple (Malus sp.) canopy (Henshall and Beresford, 1998, personal communication). Other workers also have attempted to mimic fruit shape in sensor construction (Sutton et al., 1984).

There have been many attempts to develop alternatives to conventional electronic sensors. Armstrong et al. (1993) found a beta-ray gauge gave reasonable agreement with visual observations both in the field and in the laboratory. The beta-ray gauge has a detection limit of a water layer of $0.0012 \mathrm{~mm}$ thickness with $95 \%$ probability (Bunnenburg \& Kuhn, 1977). It also has the advantage of using the leaf surface rather than an artificial surface to measure surface wetness, but internal hydration of leaves in the evening may obscure an accurate determination of dew onset and the sensor itself may interfere with dew deposition. The sensor is unlikely to see routine adoption for surface wetness measurement due to its high cost. Although the detector is inexpensive, the rate-meter electronics for the detector are comparable to the costs of a high-end datalogger.

Researchers also have tested radar (Gillespie et al., 1990) and microwave transmission as tools for estimating wetness duration or water interception (Bouten et al., 1991; Wigneron et al., 1996). The main problem with these techniques is that the internal plant and surface moisture status influenced the signal. Another recent development with considerable promise is the use of infra-red thermometry to estimate surface wetness (Deshpande et al., 1995; Sadler, 1996). This technique estimates surface wetness from the time period during which the dew point or wet bulb temperature of the air is greater than the canopy temperature. The advantage of this technique is that the infra-red thermometer measurement is representative of a large area relative to an electronic sensor, and has the potential to be used in combination with remote sensing techniques. The limitations of this technique include: cost of the IR sensor; inaccurate estimation of the dry-off phase and calibration of the background temperature. The last problem arises because the leaf and water are not perfect emitters, so they reflect a small amount of the sky radiation back into the thermometer (Fuchs \& Tanner, 1966).

In turf canopies, conventional sensors are often impractical. One experimental alternative is a spectroradiometric approach that uses canopy reflectance to measure wetness in turf canopies (Madeira et al., 2001). Canopy reflectance in the middle infra-red range at $1.165 \mu \mathrm{m}$ was strongly correlated to surface wetness. The technique worked well in the very short turf grass of a frequently mowed golf green where leaf orientation is near vertical, but it was not as successful in a taller grass canopy with variable leaf orientation such as a golf fairway. 
Some authors have suggested a relative humidity threshold as surrogate for surface wetness (Sutton et al., 1984; Wilks \& Shen, 1991). Peltier cooled dew point sensors can be an inexpensive and reliable method to determine relative humidity (Bailey, 1999; Griffieon et al., 1992; Vancauwenberghe et al., 1996), although dirt deposits on the mirror surface may compromise their performance (Griffieon et al., 1992). Vincelli and Lorbeer (1988) found that relative humidity could be used to estimate missing surface wetness data; however, several other studies have shown there is a relatively poor correlation between periods of high humidity and surface wetness (Francl \& Panigrahi, 1997; Lomas \& Shashoua, 1970; Wallin, 1963). The use of high relative humidity instead of surface wetness may result in an overestimation of plant disease risk (Jones et al., 1980).

\section{Surface Wetness Models}

An alternative to the use of sensors is the simulation of surface wetness (Huber \& Gillespie, 1992; Weiss, 1990). Simulation also enables surface wetness to be determined from historical or forecast weather data. Later, it will be seen that surface wetness can be determined without the need for an on-site automated weather station by using simulated weather inputs created by site-specific weather technologies. Despite these advantages, surface wetness models have not been widely used for reasons that will be discussed later.

Models for the determination of surface wetness can be divided into two broad categories, statistical or physical. In the former approach, a statistical relationship is produced between atmospheric variables and surface wetness. Statistical models can be based on linear regression, analytical classification, neural networks, or combinations of these techniques (Chitou et al., 1999; Crowe et al., 1978; Francl \& Panigrahi, 1997; Galliani \& Screpanti, 1993; Gleason et al., 1994). One of the most successful statistical models is the Classification And Regression Tree (CART) model (Gleason et al., 1994). CART uses the dew point depression, wind speed, and relative humidity to classify hours as wet or dry. Given the complexity between the interactions of meteorological variables and the formation of surface wetness, the determination with a statistical model is difficult (Crowe et al., 1978). Although significant statistical relationships can be shown, there is a concern about the applicability of the models to sites and/or crops other than those at which they were developed (Francl \& Panigrahi, 1997). An alternative to the statistical model is a physical approach using a water budget and a surface energy balance.

Surface energy balance models have been used since the 1950s to estimate evaporation (Penman, 1948), but applications to predict surface wetness have been more recent. Pedro and Gillespie (1982a,b) developed a well-known leafscale dew model, and Thompson (1982) was one of the first to use a multilayer canopy model for estimation of surface wetness. Recently, a big leaf model known as the Surface Wetness Energy Balance (SWEB) model (Magarey, 1999) has been developed as a potential theoretical standard for surface wetness measurement. The SWEB model has been calibrated to the drying of drops and films under controlled atmospheric and radiative conditions in a wind tunnel and a lab- 
oratory setting (Magarey et al., 2004). In the SWEB model the canopy water budget is

$S=I+D-E$

where $S=$ water storage, $\mathrm{cm}, 0<S=C$,

$C=$ canopy water storage capacity, $\mathrm{cm}$,

$I=$ intercepted rain or irrigation, $\mathrm{cm}$,

$D=$ volume of water condensing on the leaf as dew, $\mathrm{cm}$, and

$E=$ volume of water evaporating, $\mathrm{cm}$.

Surface wetness occurs when the canopy water budget $(S)$ is positive. The interception term $(I)$ is a function of the leaf area index (LAI) and precipitation or irrigation. There are a large number of interception models in the literature (Huber \& Gillespie, 1992). Many of these models are complex and rely on empirical drainage parameters that may change with canopy size and type. For most applications, a simple interception formulation is most appropriate, for example, Norman and Campbell (1983)

$I=(1-\exp (-0.5 \mathrm{LAI})) P$

where LAI = leaf area index, dimensionless, and $P=$ precipitation as rain, $\mathrm{cm}$

The amount of water condensing $(D)$ on and evaporating $(E)$ from the canopy surface is derived from the combination of surface energy balance and aerodynamic transport equations (Tanner \& Fuchs, 1968). This combination equation is shown below in energy units for potential evaporation. For a wet plant organ, the actual evaporation is proportional to the wet area.

$E=E_{\mathrm{p}} W=\Delta /[\lambda(\Delta+\delta)]\left\{R_{\mathrm{n}}+\rho C_{\mathrm{p}}(h / \Delta)\left(e_{\mathrm{a}}^{*}-e_{\mathrm{a}}\right)\right\} W$

where $E_{\mathrm{p}}=$ potential latent heat flux density (evaporation), $\mathrm{cm} \mathrm{min}^{-1}$,

$\Delta=$ slope of the saturation vapor pressure curve, $\mathrm{mb} \mathrm{C}^{-1}$,

$\lambda=$ latent heat of vaporization, $\mathrm{J} \mathrm{g}^{-1}$,

$\delta=$ psychrometric constant, $\mathrm{mb} \mathrm{C}^{-1}$,

$R_{\mathrm{n}}=$ net radiation flux density, $\mathrm{J} \mathrm{min}^{-1} \mathrm{~cm}^{-2}$,

$\rho=$ density of air, $\mathrm{g} \mathrm{cm}^{-3}$,

$C_{\mathrm{p}}=$ specific heat of air, $\mathrm{J} \mathrm{g}^{-1} \mathrm{C}^{-1}$,

$h=$ transfer coefficient for heat and vapor from the surface to the atmosphere, $\mathrm{cm} \mathrm{min}^{-1}$,

$e_{\mathrm{a}}=$ water vapor pressure of the atmosphere, $\mathrm{mb}$,

$e_{\mathrm{a}}^{*}=$ saturated water vapor pressure of the atmosphere, $\mathrm{mb}$, and

$W=$ fraction of wet surface area, dimensionless

Many surface wetness models have been developed. Huber and Gillespie (1992) listed at least 16 models capable of simulating surface wetness and many 
others have been developed since this 1992 review was published. Physical surface wetness models can be developed at three different scales: drop, organ (leaf or fruit) and canopy (Huber \& Gillespie, 1992). The main problem with the dropscale models is the complexity of modeling droplet shapes that can vary with leaf wettability, rain or dew, and change during drying (Leclerc et al., 1985; Barr \& Gillespie, 1987). The Pedro and Gillespie (1982b) leaf-scale dew model is well known and has been adapted to several different crops. Fruits, because of their greater heat capacity, accumulate and lose surface wetness more slowly than leaves. They also differ in water holding capacities and other physical properties compared with leaves. Models have been developed for cocoa (Theobroma cacao L.) pods (Butler, 1980; Monteith \& Butler, 1979), grape clusters (Vitis sp., Huber et al., 1991) and sunflowers (Helianthus annus L., Payen, 1983). Finally, there are multilayer models (Huber \& Itier, 1990; Thompson, 1982) where a water budget for a whole canopy is considered. These models can provide a comprehensive picture of the wetness of a canopy. The disadvantage of the canopy models is that they are complex and often require a large number of input parameters that may limit their operational capabilities.

Models to predict surface wetness are usually run using hourly weather data, although it may be possible to produce satisfactory results from daily data (Weihong \& Goudriaan, 1991). These inputs should be collected above the crop canopy (microclimate scale), but techniques have been developed to run models from standard weather station data (Pedro \& Gillespie, 1982b). Most simulation models of surface wetness require the following atmospheric inputs: air temperature, relative humidity or vapor pressure, wind speed, and long wave sky radiation (Magarey, 1999). Of these inputs, the long-wave sky radiation is rarely operationally measured, but it can be estimated empirically from other variables including cloud cover and temperature (Linacre, 1992; Monteith \& Unsworth, 1990). Madeira et al. (2002) showed that a simple energy balance model could effectively determine surface wetness duration from cloud cover and air temperature. Another important input is soil moisture; Wilson et al. (1999) found that it extended surface wetness by about $2 \mathrm{~h}$ in a potato (Solanum tuberosum L.) canopy. For determining surface wetness from dew, the use of an energy balance model is relatively easy if atmospheric turbulence can be properly parameterized and reliable long-wave sky radiation data are available. For surface wetness from rain, the spatial variability in precipitation may be a serious impediment to the simulation approach.

In addition to the atmospheric and soil inputs there also are plant-dependent parameters necessary for the simulation of surface wetness. Typically, physically based surface wetness models have four crop-dependent parameters: crop height; leaf area index (LAI); maximum water storage; and leaf wettability (Huber \& Itier, 1990). Maximum water storage for a leaf or other plant organ can be easily measured in the laboratory (Barfield et al., 1973) and determined for the whole canopy using the LAI. The LAI can be measured by destructive sampling, with a sensor such as a canopy analyzer or estimated from a simulation model. Leaf wettability can be incorporated into a model using a simple drop-shape parameter and hysteresis relationship (Huber, 1988; Huber \& Itier, 1990). Leafsize is an additional consideration that could be included in a model that used a 
leaf scale energy balance. In the dry-off phase, leaf length can be safely ignored, as it has been shown that droplet boundary layer depth is greater than that of the leaf, i.e., drops usually protrude beyond the leaf boundary layer for most of their life (Leclerc et al., 1986); however, leaf-size is important for onset of wetness because it controls the leaf temperature and hence the time when the leaf reaches the dewpoint temperature. Although the crop dependent parameters enable adaptation to different crops, in practice, few simulation models have been tested on more than one crop. One exception is the Pedro and Gillespie (1982b) model that has been adapted to apple, corn, soybean, banana (Musa sp.), and lettuce (Laetuca serrida L., Gillespie \& Barr, 1984; Lhomme \& Jimenez, 1992; Pedo \& Gillespie, 1982b; Scherm et al., 1995). The Pedro and Gillespie model was transferable to a new crop and site with the exception of the empirical equation that linked crop and weather station air temperature.

\section{USING SENSORS AND SIMULATION MODELS}

\section{Simulation from Site-Specific Simulated Observations and Forecasts}

In recent years, technologies have been developed to estimate site-specific weather data remotely (Magarey et al., 2001; Russo, 2000). Estimated site-specific weather data can be either simulated observations or forecasts. Simulated observations use interpolation schemes to estimate weather conditions for a site by using data from surrounding weather stations. Variables used to generate simulated observations include terrain slope gradient, aspect, and elevation, and proximity to ocean and reference stations (Kuuseoks, 1997; Seem et al., 1991). Simulated site-specific data for continuous variables, such as temperature and radiation, are good to excellent, while data for discontinuous variables, such as precipitation and cloud cover, are poor to fair (Gleason et al., 1997; Kusseoks et al., 1997; Magarey et al., 2001; Seem et al., 1991).

While simulated observations can indicate what has happened in a farmer's field, site-specific forecasts allow anticipation of future events. In the past, synoptic-scale models were the standard for weather forecasts, but these have coarse resolution (grid sizes $>100 \mathrm{~km}$ ). More recently, mesoscale models (Mahfouf \& Jacquemin, 1989; Manobianco et al., 1996) are being used to generate forecasts at a much higher resolution ( 5 to $50 \mathrm{~km}$ ). Site-specific forecasts, can be created by downscaling mesoscale output to a higher spatial scale, through additional processing either at the local or canopy scale (Fig. 10-1) (Seem et al., 2000). An example is the Model Output Enhancement (MOE) technique (Kelley et al., 1988) where mesoscale information is interpolated to the local scale using $1 \mathrm{~km}^{2}$ digital terrain data. The technique operates by: (i) interpolating upper air forecasts from mesoscale numerical model output to approximately $1 \mathrm{~km}^{2}$; (ii) extrapolating the interpolated data to the surface using theoretical and observed atmospheric processes; and (iii) adjusting the extrapolated surface values with digital terrain data (Royer et al., 1989). Other surface data such as land use also may be used to calibrate the forecasts. The MOE forecasts represent a generic weather station environment, a greater level of downscaling is required to represent the specific microclimate of a plant canopy. 


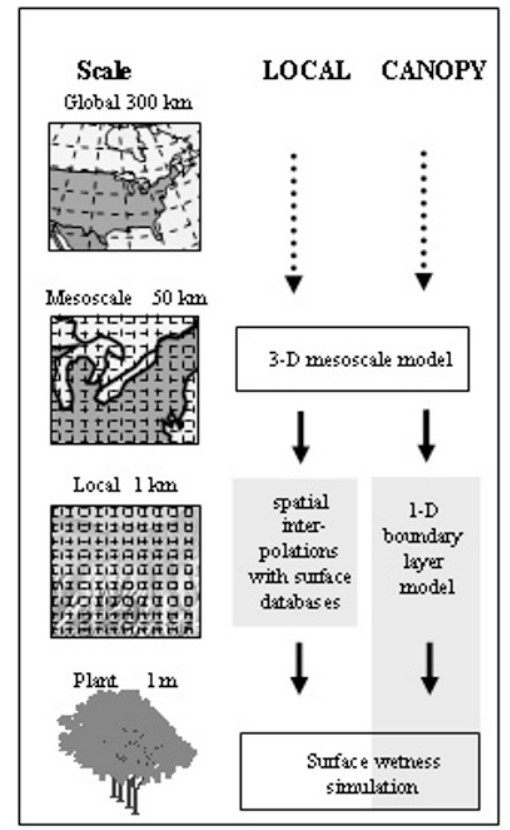

Fig. 10-1. A comparison of two techniques for creating site-specific forecasts from mesoscale model output (modified from Seem et al., 2000).

In many instances, it may be possible to downscale to a canopy environment by making simple empirical corrections. Kim et al. (2002) used a correction to estimate wind speed at canopy height from a reference height forecast produced by a modified MOE technique. The corrected wind speeds improved the estimation of surface wetness when used as input into the CART statistical surface wetness model (Gleason et al., 1994). A more complex example of downscaling at the canopy level is the Canopy-Mesoscale Forecast System (CMFS) (Seem et al., 2000). The CMFS is a one-dimensional canopy model that is coupled to the mesoscale model (Fig. 10-1). The one-dimensional vertical model is a column of points from the upper portion of the soil to the lower stratosphere. It uses the same equations as the three-dimensional mesoscale model, but since only vertical processes are included, it can have high vertical resolution (on the order of $1 \mathrm{~m}$ ). The one-dimensional model incorporates site-specific information for parameters such as surface heat capacity, albedo, and leaf area index that cannot be included in the three-dimensional model because of its much coarser horizontal resolution.

Seem et al. (2000) evaluated 12-h forecasts of surface wetness from a CMFS model in grapes. Measurements of surface wetness made by an etched circuit board sensor were used to compare three surface wetness simulations: (i) a preliminary version of the SWEB model (Magarey, 1999) run from microclimate input data; (ii) a proprietary model (E-weather surface wetness, SkyBit, Inc. Bellefonte, PA) run from 24-h forecast input provided by a system based on the MOE; and (iii) a big leaf model (Zack, 1996, unpublished data) run from 12-h 
CMFS forecasts. The simulations were compared with measurements using the critical success index (CSI) (Wilks, 1995), which is discussed later. The SWEB model, run from mircoclimate data was the most successful $(\mathrm{CSI}=0.76)$, the CMFS system was less effective $(\mathrm{CSI}=0.69)$ and the MOE forecast was the least effective $(\mathrm{CSI}=0.45)$. The 12-h forecasts from the CMFS captured the trend of surface wetness in the canopy but were cruder than the model run from microclimate data (Fig. 10-2).

Another related downscaling study used the ALEX model to determine surface wetness in potatoes (Anderson et al., 2001). The ALEX model is a simplified form of the CUPID model (Norman \& Campbell, 1983) and describes the transport of heat, water vapor, $\mathrm{C}$, and momentum within the soil-plant-atmosphere system using the principles of energy balance and turbulent exchange (Anderson et al., 2000). The authors showed that the ALEX model could successfully simulate surface wetness using microclimate input, and canopy relative humidity using a regional scale weather network and satellite input data (Anderson et al., 2001).

In the same way that forecast data can be used as input, surface wetness models can be run from historical weather or climate data. In the past, surface wetness climate databases have not been commonly constructed because of the problems associated with poor standardization or a lack of available data. Bass et al. (1991) developed a climatic surface wetness database for Canada using a drop model for estimation of surface wetness from rain (Zhang \& Gillespie, 1990), the

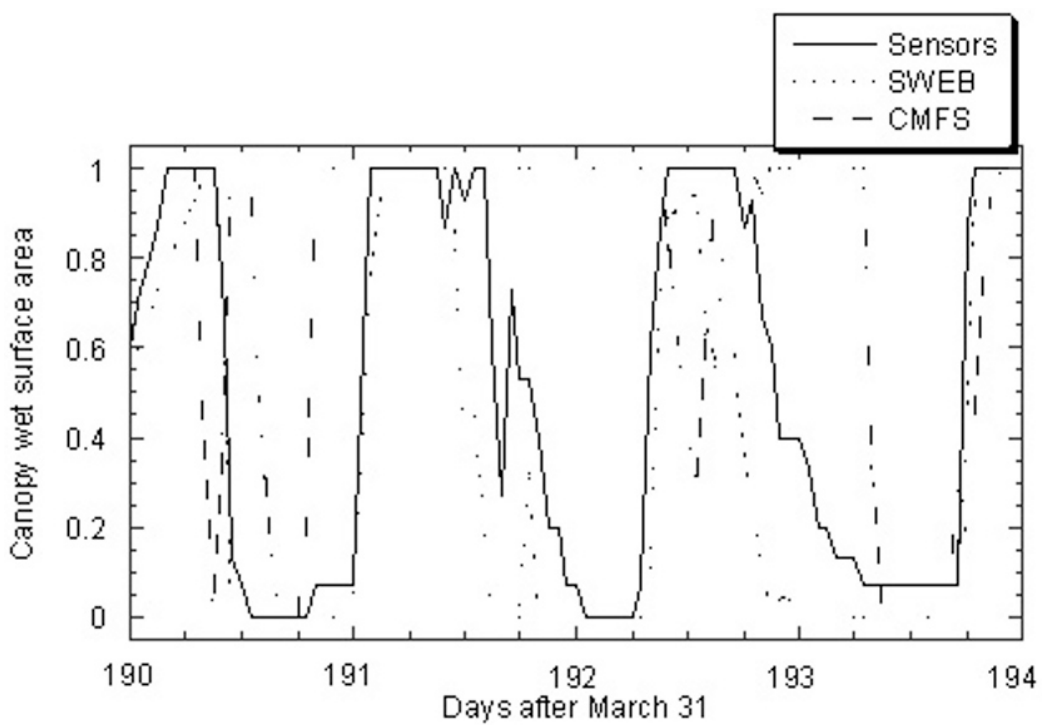

Fig. 10-2. A comparison of measured and simulated canopy wet surface area in grapes during a 5-d period. Measurements were made with 15 painted Campbell scientific sensors in five canopy locations. Simulations were made with a preliminary version of SWEB run from microclimate data and a Canopy-Mesoscale Forecast System (CMFS) using 12-hour simulated site-specific forecasts (modified from Seem et al., 2000). 
dew model of Pedro and Gillespie (1982b) and an empirical estimator of LAI. The models were run using hourly weather observations for six Canadian climate stations from a 35-yr period. The study used a Gumbel distribution to generate the probability of the occurrence of 24-h of surface wetness (Fig. 10-3). The results showed substantial differences between the six stations and have application for selecting sites with low fungal disease pressure.

\section{Calibration and Validation of Sensors and Models}

Calibration is the process whereby a position on the scale of an instrument is identified with the magnitude of the signal actuating that instrument (Huschke, 1959). Sensors must be calibrated to the observed surface wetness on a plant part or in a plant canopy. Electronic sensors can be calibrated by adjusting the wet-dry transition threshold, which is an impedance value at which the surface is classified as wet. This comparison of sensor readings to visual or tactile observations can be done in a controlled environment, or it can be done in the field. In a controlled environment, sensors have been calibrated by either dry-off or condensation studies or a combination of both. In dry-off studies sensors are wetted and then allowed to dry in a controlled environment (Butt \& McGlinn, 1989; Miranda et al., 2000; Potratz et al., 1994). In condensation studies the sensor output is compared with the condensation and dry-off of surface water in a surface wetness

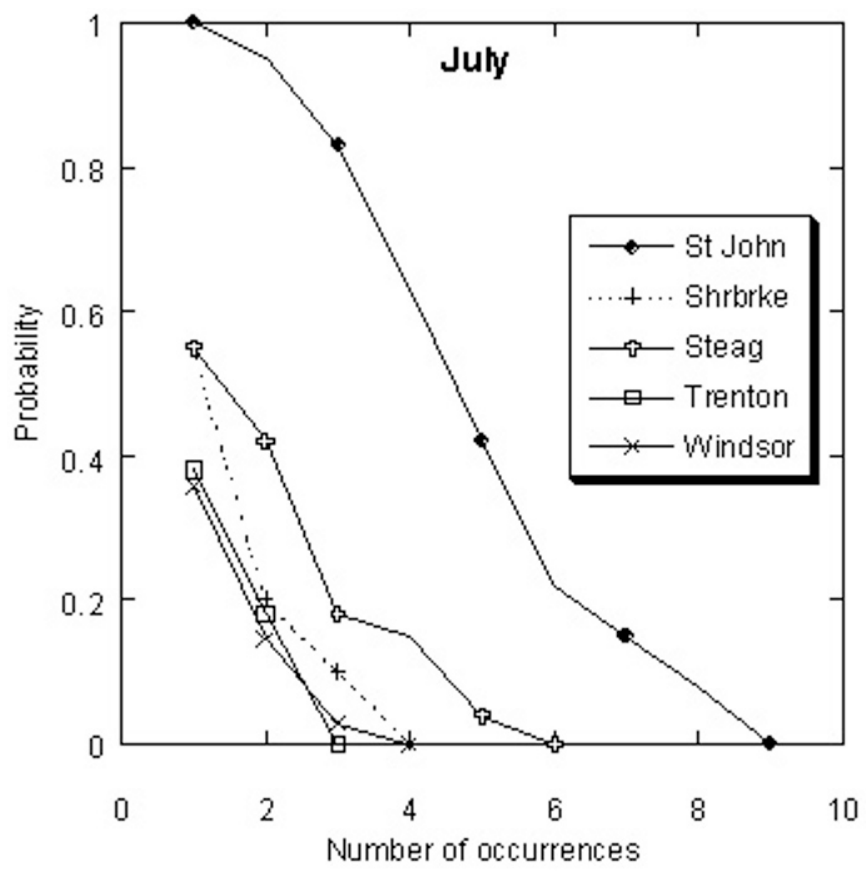

Fig. 10-3. Estimation of frequency of leaf wetness periods that exceed 24-h at five Canadian climate stations during the month of July (Bass et al., 1991). (Used with permission from Elsevier). 
(dew) chamber (Armstrong et al., 1993; Weiss et al., 1988). The surface wetness chamber should emulate natural dew events by producing radiative cooling, for example with a blackened copper plate on a controlled temperature heat exchanger to represent an artificial night sky (Weiss et al., 1988). For both studies, the sensor output can be compared with either visual observation of dryness (Potratz et al., 1994) or the remaining volume of water determined by weight (Miranda et al., 2000).

Surface wetness sensors are most commonly calibrated in the field (Giesler et al., 1996; Gillespie \& Duan, 1987; Gillespie \& Kidd, 1978; Huband \& Butler, 1984; Lau et al., 1999; Potratz et al., 1994; Weiss \& Lukens, 1981). In the field, a commonly used calibration method is to compare visual observations or tactile observations of surface wetness on the crop with sensor output. There is no one recognized protocol for this technique. Potratz et al. (1994) proposed a simple protocol for sensor calibration; the observation of water droplets with a flash light and hand lens at six sites adjacent to the surface wetness sensors. The observations are made at 20-min intervals. The task may be simplified by using a twoway radio to communicate results between an observer and a recorder. The protocol may need to be amended to include observations on other plant organs such as stems or fruit surfaces. Visual observations are tedious to collect and usually have limited temporal and spatial resolution. Simulation models can be calibrated to a given crop by comparison of the output units to visual observations or measurements made by sensors. In practice, few models have received field calibration, partly because no model has emerged as a standard. Another reason has been that calibration and the more fundamental task of the validation of surface wetness models is quite difficult and/or time consuming. Some surface wetness models have been validated under controlled conditions (Leclerc et al., 1985; Magarey, 1999), but most are too complex to be tested at the leaf scale. Although most surface wetness models have received some field validation (Barr \& Gillespie, 1987; Hoppmann \& Wittich, 1997; Madeira et al., 2002; Pedro \& Gillespie, 1982b; Thompson, 1982; Weiss et al., 1989; Zhang \& Gillespie, 1990), the validations have been inhibited by the lack of standards for defining and measuring surface wetness (Anonymous, 1990). Many validation studies only compare simulations with sensors (Gleason et al., 1997; Madeira et al., 2002; Scherm et al., 1995; Seem et al., 2000; Thompson, 1982). Although these validations are useful and often represent the only available method for some types of studies, they create the impression that simulation is less accurate than measurement. This assumption has never been tested. Some validations have included visual observations but the authors did not use a statistical comparison of simulated and observed values (Hoppmann \& Wittich, 1997; Pedro \& Gillespie, 1982a; Wittich, 1995). One study used the leaf as the sensor surface (Weiss et al., 1988), but this is impractical for many situations.

\section{Protocol}

\section{Placement of Sensors in the Canopy}

There is no single accepted protocol for the use of sensors, although there is now enough information to make solid recommendations about compass and 
vertical orientation, location within the canopy, and the deployment number (Giesler et al., 1996; Penrose \& Nicol 1996; Potratz et al., 1994). Compass orientation has little influence upon surface wetness duration if the etched circuit board sensor is painted (Lau et al., 1999), although prevailing wind direction may be important in an unsheltered situation. Gillespie and Kidd (1978) suggest that the sensor should be tilted to prevent pooling of water that may result in an overestimation of leaf wetness. A common practice is to tilt the sensor on its short axis at an angle of $45^{\circ}$.

The best site for a sensor is just below the top of the canopy (arguably, three quarters of the canopy height) but exposed to the night sky. The top of the canopy has the greatest surface wetness from dew (Jacobs et al., 1990; Potratz et al., 1994; Weiss et al., 1989) and a position below the canopy top provides some protection from the wind and early morning sun.

Most automated weather stations that measure surface wetness rely on a single sensor, which can lead to an imprecise measurement. Indications are that three sensors should be used for a precise determination. Penrose and Nicol (1996) found that a single sensor had a probability of 0.6 of detecting a wetness event in an apple tree and three sensors would have a probability of 0.92 . Another study in grape showed that three sensors will produce $95 \%$ certainty that surface wetness is being measured with an error between 1 and 2.5 h (Fig. 10-4.) (Magarey, 1999).

\section{Painting of Sensors}

Etched circuit board sensors commonly used to measure surface wetness, are often painted to make their response closer to that of leaves or other green plant parts. Latex paint distributes water uniformly, allowing droplets smaller than the gaps within a grid to create a sensor response (Gillespie \& Kidd, 1978).

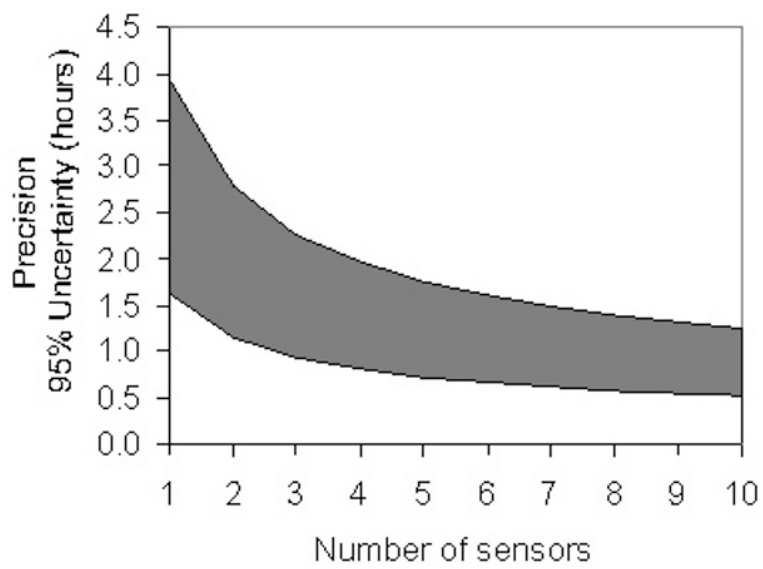

Fig. 10-4. The relationship between the number of sensors and the uncertainty of measurement of surface wetness. The band represents the range of uncertainties found in seven canopy trials in grape (modified from Magarey, 1999). 
Another important influence of painting is that it allows the sensor to mimic the radiative response of a leaf. Unpainted sensors have been shown to underestimate the onset of dew events by as much as $4 \mathrm{~h}$ (Lau et al., 1999).

It is necessary to use a water-based latex paint that transmits moisture but avoids a hygroscopic response. This response will cause the sensor to react to high humidity (rather than just liquid water), which is obviously undesirable. The hygroscopic response occurs because of certain components in the fresh paint. In general, the least expensive paints contain the fewest hygroscopic components, but the following treatment is required for their complete removal (Gillespie, 1977, unpublished data). Once the paint is applied (by spraying or dipping), dry the sensor at about $100^{\circ} \mathrm{C}$ for a day. A soil-drying oven is a good choice for this task since it can be easily maintained at this temperature and is readily available in many agricultural labs. Check for a high relative humidity $(\mathrm{RH})$ response by enclosing the sensor in a plastic bag containing an open beaker of water at room temperature. If the sensor responds in this environment, soak it in deionized water for several hours and repeat the drying at $100^{\circ} \mathrm{C}$. Check the sensor again in the plastic bag and, if necessary, repeat the soaking and drying cycle until the high RH response disappears.

Gillespie and Kidd (1978) found that sensors painted off-white were the most suitable. They found that sensors of colors other than white underestimated wetting in comparison with visual observation on real onion leaves. Sensors need to be a lighter color than real leaves to compensate for much stronger absorption of near infra-red radiation by paint than by foliage. Over a full season, a light gray or light green color is more suitable because it is less likely to be discolored than off-white (Sutton et al., 1984). This color may be achieved with about 125 parts white paint combined with 20 parts water (to avoid too thick a paint coat) and 1 part green tint (phthalocyanine) (Gillespie $\&$ Duan, 1987). The degree of tinting required to match a particular crop type can be determined by comparing the surface wetness of the crop with mock sensors of different tints.

\section{Sensor Maintenance}

Maintenance will depend upon the individual sensors. Most etched circuit board sensors will require thorough cleaning and painting at least once each season. They also should be inspected once every two weeks to remove contaminants. This includes honeydew and frass from insects and droppings from birds, all of which may cause sensors to overestimate surface wetness (Weiss \& Hagan, 1983). Some pesticides, especially those that contain copper, can be particularly detrimental to the performance of etched circuit board sensors.

\section{Protocol Considerations for Simulation}

No protocol guidelines have been established for simulating surface wetness but the atmospheric and crop inputs should be collected according to established protocols. For these protocols, see the other chapters in this book. 


\section{DATA COLLECTION AND ANALYSIS}

\section{Error and Uncertainty Analysis}

All measurements should be supported by an estimate of the probable magnitude of the uncertainty (Anonymous, 1983). Surface wetness measurement is subject to four types of uncertainty - precision (repeatability), accuracy (comparison with a standard, in this case visual observations), protocol, and uncertainty due to scale.

\section{Precision of Measurement and Simulation}

Precision may be expressed simply as the standard deviation, but it is more commonly expressed as a 95\% confidence limit (Mowrer, 1999; Snedecor \& Cochran, 1989). The $95 \%$ uncertainty due to precision for painted etched circuit board sensors (Model 237, Campbell Scientific, Logan, UT) used with the discussed protocol is usually about $2 \mathrm{~h}$ (Magarey, 1999; Potratz et al., 1994). Magarey (1999) found that when sensors were used within a grape canopy the uncertainty could be as high as $5 \mathrm{~h}$. While some paint processes may increase precision (Magarey, 1999; Potratz et al., 1994) other paint processes may lower precision (Wei et al., 1995), especially between batches (D.K. Fisher, 1995, personal communication). The drying of unpainted sensors tends to be governed by large drops, unlike in a painted sensor where drops are absorbed into the paint.

The precision of a surface wetness model is estimated using the assumption that the model represents a perfect black box (Mowrer, 1999; Russo et al., 1993). The precision depends upon the sensitivity of a model to its inputs and the magnitude of the uncertainties associated with these inputs. In general, simulation models are highly sensitive to relative humidity, moderately sensitive to wind speed and net radiation, and relatively insensitive to temperature (Huber, 1988; Magarey, 1999; Scherm \& van Bruggen, 1993). Huber (1988) found that increasing relative humidity from 75 to $95 \%$ increased simulated surface wetness by $5 \mathrm{~h}$ in a multi-layer simulation. In comparison, increasing the wind speed from 1.5 to 3.5 $\mathrm{ms}^{-1}$ or net radiation from 200 to $400 \mathrm{Wm}^{-2}$ increased surface wetness by $2 \mathrm{~h}$. Canopy-scale models and multilayer models are sensitive to LAI and the amount of rain intercepted or the type of rainfall interception model used (Huber 1988; Mahfouf \& Jacquemin 1989; Watanabe \& Mizutani, 1996). Magarey (1999) found that with typical instrument errors, the $95 \%$ uncertainties for surface wetness simulation by the Surface Wetness Energy Balance (SWEB) model were relatively small $(\sim 0.3 \mathrm{~h})$ for temperature, net radiation and rain but relatively large $(\geq 1 \mathrm{~h}$ ) for relative humidity, wind speed and leaf area index. In particular, relative humidity sensors can be a source of uncertainty. In one study, a relative humidity sensor developed at least a 3\% bias during a 60-d measurement period (Andersen et al., 2001). When simulated site-specific weather inputs are used as an alternative to measurements, the uncertainties can be much greater. In formal comparisons with canopy measurements in and near Geneva, NY, during a 3-yr period, the accuracy (mean absolute error) of simulated observations of relative humidity was approximately 7\% (Magarey, 1999). 


\section{Accuracy of Measurement and Simulation}

Accuracy comparisons or analyses are often made between an accepted true estimator and a test estimator. For example, visual observations or a standard sensor or model are compared with a new type of sensor or model. Other common accuracy comparisons are between an on-site sensor and a sensor either offsite or at a different height or location in the canopy. In addition, accuracy comparisons are often required for surface wetness data produced by simulation models that are run from weather inputs collected outside of the canopy. Commonly, comparisons use the daily totals of surface wetness hours (Gleason et al., 1994), the length of individual wetness periods (Magarey, 1999) or the time of wetting and drying (Potratz et al., 1994). For these types of comparisons, the mean absolute error, the root mean squared error or the mean and standard error of the differences between the true and test estimator can be used (Snedecor \& Cochran, 1989; Wilks, 1995). Another method is to compare the proportion of hours that are correctly classified as wet and dry using a dichotomous categorical verification. In this case an accuracy measure for binary data such as the critical success index can be used (Wilks, 1995). The critical success index (CSI) is

$\mathrm{CSI}=a /(a+b+c)$

where $a, b, c$, and $d$ are the counts for a dichotomous categorical verification (Table 10-1).

A commonly used etched circuit board sensor (Campbell Scientific, Model 237) has an accuracy (mean absolute error) of $<1 \mathrm{~h}$ when painted (Magarey 1999; Potratz et al., 1994). The World Meteorological Organization made an early recommendation that leaf wetness should be measured with an accuracy of $\pm 0.5 \mathrm{~h}$ (Lomas \& Shashoua, 1970). This recommendation can be justified from the biological importance of time periods as small as $30 \mathrm{~min}$ in plant disease epidemics.

There has been no agreement in the literature as to which surface wetness models are the most accurate. Although, many statistical models have shown high correlations with measurements, some have only been tested at a single site (Chtioui et al., 1999; Francl \& Panigrahi, 1997; Galliani \& Screpanti, 1993; Muller, 1992). One exception is the CART Model, which has received widespread validation over the mid-west of the USA and beyond (Francl \& Panigrahi, 1997; Gleason et al., 1994; Kim et al., 2002). The Pedro and Gillespie (1982a) model and the CART Model are two of the most widely used in the literature, but apart from these, there have been few comparisons of models in the literature. In one study, Madeira et al. (2002) found that the CART Model had a mean absolute error of $2.4 \mathrm{~h}$ compared with $1.5 \mathrm{~h}$ for a simple energy balance model. Another

Table 10-1. Dichotomous categorical verification for accuracy comparisons for surface wetness estimation.

\begin{tabular}{lccc}
\hline & \multicolumn{2}{c}{ True estimator } \\
\hline Number of occurrences & wet & dry \\
\hline Test & wet & a & b \\
Estimator & dry & c & d \\
\hline
\end{tabular}


study (Francl \& Panigrahi, 1997), found that the CART Model had a mean square error of $0.54 \mathrm{~h}$ compared with $2.39 \mathrm{~h}$ for the Pedro and Gillespie Dew Model.

The accuracy of models, using simulated site-specific weather data as input, to determine surface wetness is improving and in some cases approaches the accuracy of sensors. Simulated observations of surface wetness (E-weather, SkyBit, Inc., Bellefonte, PA) may be comparable to sensors when sensor precision is taken into consideration (Gleason, 1997, personal communication; Magarey, 2001, unpublished data). Surface wetness simulations from forecast input are less accurate than those from simulated observations due to greater uncertainties in the input data (Muller, 1992; Scherm et al., 1995; Seem et al., 2000). Although accuracy is an important consideration, other operational factors as discussed below, are likely to determine which models become the most widely adopted.

\section{Uncertainty Due to Scale}

The uncertainty due to scale is associated with variability of a phenomenon over a defined space and time (Mowrer, 1999; Russo et al., 1993). For example, surface wetness may be measured at a single location in a field but a field is rarely uniform in soil or crop features. The importance of canopy-scale uncertainty depends upon the canopy geometry and climate. In field crops, the top of the canopy may dry more rapidly than the bottom. A variation of from 6 to 10 ho has been observed in field bean (Phaseolus vulgaris L.) canopies (Huber \& Itier, 1990) and from 3 to $5 \mathrm{~h}$ in an onion crop (Sutton et al., 1984). Another factor is that the top of the canopy may receive earlier and greater volumes of dew deposition and consequently have greater surface wetness duration (Jacobs et al., 1990; Weiss et al., 1989). In semi-arid climates, where distillation may be more important than dewfall, the lower portions of the canopy may receive greater dew deposition (Garrat \& Segal, 1988). Although there are always wet and dry pockets, tree or vine crops may have a relatively uniform environment simply because wind can circulate above and beneath the canopy (Penrose \& Nicol, 1996).

Less effort has been devoted to the uncertainty due to scales beyond that of the canopy. There are few accounts of the variability of surface wetness within a field. Penrose and Nicol (1996) examined the variability in surface wetness between farms within a district. Seven sites were examined within a 20 -km radius and only on approximately $5 \%$ of wet hours were all sites wet at the same time. Sites within a 5-km radius had the same total hours of wetness, but a more distant site, $20 \mathrm{~km}$ from the central point, had significantly more wetness.

\section{Error Checking}

Any unusual output signal should be investigated if it has rained and the sensor output indicates no surface wetness or vice-versa. Sensor placement, location and operation should be evaluated. It also may be necessary to visually observe occurrences of surface wetness to compare with sensors. Simple checks can be made to determine if the sensor has failed (P. Magarey, 2002, personal communication). For example, one possible method is to flag surface wetness values as being erroneous if there is rain or $100 \%$ relative humidity but no surface wetness during any given time period. Another common error, is a continuously 
wet reading, which may occur with etched circuit board sensors when the surface becomes contaminated. In this case, we suggest surface wetness should not exceed $18 \mathrm{~h}$ if there was no rain or overhead irrigation recorded in the current or previous day. In the case of a surface wetness model, any errors in the input data will be reflected in the model output.

\section{Standardization}

The major problem with estimation of surface wetness is the variability between different types of sensors (Butt \& McGlinn, 1989) and consequently, the lack of standards for measurement (Anonymous, 1990; Wallin, 1967). The absence of a standard prevents the exchange of data when different instruments or protocols are used for measurement. We suggest three options to address these problems: (i) an internationally accepted standard sensor design; (ii) standardized criteria for sensor design based on physical plant properties; and (iii) a theoretical standard based on a simulation model.

The following design, although not necessarily superior to other designs can be suggested as quasi-standard because of its widespread use: An approximately square etched circuit board sensor with a surface area about $50 \mathrm{~cm}^{2}$ and 1 mm thick (Gillespie \& Kidd 1978). The electrodes should be approximately 1 mm wide, with $1 \mathrm{~mm}$ separations (Davis \& Hughes, 1970; Gillespie \& Kidd 1978; Weiss \& Hagan 1983). The sensor should be painted, calibrated, and used according to the protocols defined in the previous sections.

An interesting alternative is to specify design criteria based upon the physical characteristics of plant surfaces. The specifications for the Plant Characteristic Standard sensor are defined in Table 10-2. Although non-wettable leaves may have water droplet contact angles $130^{\circ}$ (Crisp, 1963), above $90^{\circ}$ (a hemisphere) the minimum wet surface area only decreases slowly (Brewer et al., 1991). The values in Table 10-2 represent typical values for leaves, but it is possible to use the same approach to specify a standard for a particular crop or fruiting body. This approach has the distinct advantage over a conventional standard specification in that it allows manufacturers the freedom to innovate in both materials and designs. Importantly, we feel that nanofabrication technology will see the development of a new generation of radically different sensors over the next $10 \mathrm{yr}$. This development would allow construction of very small sensors the size of a computer microchip, which in turn could be attached directly to a plant surface.

A theoretical standard offers many advantages compared with a standard sensor. One only needs plant and soil properties and atmospheric variables to determine surface wetness. This approach means surface wetness can be estimated from historical datasets or forecast conditions. For measurement, sensors can be compared with a theoretical standard to determine their precision and accuracy, and their calibration. The theoretical standard can be easily distributed, updated and used by the scientific community. For example, the SWEB model has been incorporated into Metbroker, a web-based server that allows users to access weather databases around the world (Laurenson, 2002). Surface wetness simulations can be created for any weather database that has been incorporated into the Metbroker system. An additional advantage to a theoretical standard is 
Table 10-2. Specifications for a plant characteristic standard sensor.

\begin{tabular}{lll}
\hline Plant characteristic & Specification & \multicolumn{1}{c}{ Source/comments } \\
\hline Short-wave absorption 0.35 to $3.0 \mathrm{Fm}$ & 0.50 & Ross, 1975 \\
Long-wave absorption 3.0 to $100 \mathrm{Fm}$ & 0.95 & Ross, 1975 \\
Heat storage & Negligible & \\
Leaf wettability -contact angle & $>90^{\circ}$ & Brewer et al., 1991 \\
Water storage & $0.20 \mathrm{~cm}$ & Noilhan \& Planton, 1989 \\
Leaf size & Variable & $\begin{array}{l}\text { Similar to crop organ or attached } \\
\text { to crop organ }\end{array}$ \\
\hline
\end{tabular}

the international standards for the recording of the atmospheric variables that serve as model inputs (Anonymous, 1983).

Although simulation is a well-established alternative to measurement, few surface wetness models have been commonly used or accepted in agriculture. Surface wetness models in operational use include: two models used as part of commercial site-specific weather services (AWIS, Auburn, AL; SkyBit, Boalsburg, PA); an unnamed model based on neural networks used for cereal diseases (Chtioui et al., 1999; L. Francl, 2002, personal communication); a model used by the Deuthscher Wetterdienst in Germany (Hoppmann \& Wittich, 1997, 2000); two dew prediction systems in use in an agricultural advisory in the Netherlands (Garrat \& Segal, 1988; A. Jacobs, 2001, personal communication; Pedro \& Gillespie, 1982a,b). Although other models of which we are unaware may be in operational use, the majority of surface wetness data used in agriculture appear to be obtained by measurements and relatively few from simulation.

Many reasons can be given for the lack of adoption of surface wetness models including a user bias in favor of measurement, the absence of input data, the absence of a standard method or model for surface wetness simulation, and the failure of national or international agencies to adopt the simulation approach. It also is possible to identify reasons more directly related to model design. Few if any models fulfill six basic criteria for adoption. These criteria are simplicity, utility, scalability, easily observable output units, ease of adaptation to other crops and sites, and calibration under controlled conditions (Magarey, 2001, unpublished data). For example, many models have complex parameters and inputs. This complexity often makes it difficult to adapt the model to other crops (Madeira et al., 2002). Although an agricultural meteorologist easily understands the parameters in surface wetness models, this understanding is not true for most plant pathologists or other scientists who wish to use these models. Other models have been constructed for dew and do not consider rain or vice versa. Some models use output units such as latent energy or drop volume, parameters that are not easily observable in the field. As has been discussed, statistical models may not be easily adaptable to other sites. Finally, most models have not been validated or cannot be validated under controlled conditions, which increases the need for a comprehensive field validation. It seems important that one model should be accepted as a standard or a means of comparing models be developed. We suggest a comprehensive validation of models with the same input data set and comparing the output to a set of visual observations made over a range of crops. 


\section{Data Interpretation}

\section{Interpretation of Sensor Output}

The interpretation of signals from electronic sensors has nuances that must be considered. The threshold voltage or impedance level is very important in determining when a sensor changes from dry to wet and must be carefully selected. Typically, the impedance level follows a negative exponential curve as it changes from an open circuit (dry conditions) to a closed circuit (wet conditions). The impedance of a surface wetness sensor is usually measured by passing a precision voltage (excitation voltage; usually 2.0 or 5.0 volts) through a half bridge circuit that contains the sensor and a balance resistor. The return voltage is measured and typically spans from 0 , under dry conditions, to a maximum represented by the excitation voltage when the sensor is fully wet. The voltage can be converted to represent the measured impedance of the sensor where wetness is represented by low resistance. The transition from wet to dry is determined by either calibration or by user or manufacturer definition. Users of the common unpainted Campbell sensor typically program the Campbell-recommended transition threshold of $<150$ kohms. A transition threshold $<6999$ kohms has been suggested for painted Campbell sensors (Potratz et al., 1994). For those loggers that report voltage measurements, a threshold of $10 \%$ full span (maximum voltage) can be used as a representative transition value.

Electronic data loggers that sample sensors at a higher frequency than the reporting frequency have necessitated an additional interpretation. If a logger samples the sensors at 1-min intervals and reports surface wetness on an hourly basis, a question arises as to what proportion of the hour would serve as a threshold between wet and dry. In the section on definition of surface wetness, surface wetness period, and surface wetness duration, we defined surface wetness to have the temporal duration of $12 \mathrm{~min}$ within $1 \mathrm{~h}$ ( $20 \%$ of the reporting interval), however, any other proportion might be used. Both thresholds discussed here (transitional and proportional) have been defined arbitrarily, yet they represent reasonable assumptions under the present methods of surface wetness measurement.

\section{Multiple Sensors and Correction Factors}

There is little information available on how to interpret the output of multiple sensors. We suggest the relative wet area can be assumed related to the proportion of the sensors that are wet during a given hour. If sensors are at a different height, it is possible to construct a vertical surface wetness profile, but sensors placed in the canopy have greater uncertainty. A vertical profile can also be estimated with a simulation model (Huber \& Itier, 1990; Norman \& Campbell, 1983).

Another important question of interpretation is extrapolating from a turf situation (i.e., the underlying surface of a standard weather station) to the environment of a crop canopy. Potratz et al. (1994) found that a sensor over turf was a satisfactory indicator of dew in a tomato canopy; however, surface wetness caused by rain is likely to be different situation since a heavily saturated canopy will dry quite slowly, especially at the bottom. The field observations and simula- 
tions of Huber and Itier (1990) show the great variation in drying between the top and the bottom of a bean canopy. This variation would suggest that an easy correction factor may not be possible and a simulation approach may be the best alternative if additional sensors cannot be deployed.

\section{SUMMARY}

The methodology of surface wetness estimation is in a state of evolution. A website (http: http://www.nysaes.cornell.edu/swd/) has been established in an effort to encourage scientific collaboration among the diverse groups on the subject. For example, the leaf wetness home page contains a downloadable Fortran program that can be used to classify hourly leaf wetness data into wetting periods. We would like to see leading scientific organizations (e.g., American Society of Agronomy, European Society of Agronomy, American Society of Meteorology, International Society of Plant Pathology, World Meteorological Organization) recommend a standard sensor design and protocol for the measurement of surface wetness. In addition, a surface wetness simulation model should be recommended as a theoretical standard. Both recommendations would require international scientific evaluation.

It is anticipated that in the next 10 to 20 years we will see a gradual shift in the estimation of surface wetness from systems based on on-site sensors to those based on simulation models and remote sensing. As site-specific weather technologies increase in sophistication, the spatial determination of precipitation and soil moisture will improve, factors that currently limit the application of surface wetness models. We believe there will be a greater use of surface wetness data for day-to-day decision-making in agricultural and environmental applications. In particular, we see that forecasts of surface wetness will become more accurate, giving farmers and managers several days notice of possible events that may influence crop health.

\section{REFERENCES}

Analytis, S. 1977. Uber die relation zwischen biologischer entwicklung and temperatur bei phytopathogenen pilzen. (In German, with English abstract.) Phytopath. Z. 90:64-76.

Anderson, M.C., W.L. Bland, and J.M. Norman. 2001. Canopy wetness and humidity prediction using satellite and synoptic-scale meteorological observations. Plant Dis. 85:1018-1026.

Anderson, M.C., J.M. Norman, T.P. Meyers, and G.D. Diak. 2000. An analytical model for estimating canopy transpiration and carbon assimilation fluxes based on canopy light-use efficiency. Agric. For. Meteorol. 101:265-289.

Anonymous. 1983. Guide to meteorological instruments and methods of observation. WMO, Geneva, Switzerland.

Anonymous. 1990. Conclusions and recommendations of the joint WMO/EPPO/NAPPO Symp. Practical Applications Agrometeorology in Plant Protection. EPPO Bull. 21:699-700.

Armstrong, R., N.N. Barthakur, and E. Norris. 1993. A comparative study of three leaf wetness sensors. Int. J. Biometeorol. 37:7-10.

Bailey, J.E. 1999. Integrated method of organizing, computing and deploying weather-based disease advisories for selected peanut diseases. Peanut Sci. 26:74-80.

Barfield, B.J., F.A. Payne, and J.N. Walker. 1973. Surface water storage capacity of selected crop leaves under irrigation sprays. Agric. Meteorol. 12:105-111. 
Barr, A., and T.J. Gillespie. 1987. Maximum leaf wetness duration for water drops on leaves in a field. Agric. For. Meteorol. 41:267-274.

Bass, B., I. Savdie, and T.J. Gillespie. 1991. Simulation of leaf wetness duration for field corn. Agric. For. Meteorol. 57:69-84.

Bouten, W., P.J.F. Swart, and E. De Water. 1991. Microwave transmission, a new tool in forest hydrological research. J. Hydrol. 124:119-130.

Brain, P., and D.R. Butler. 1985. A model of drop size distribution for a system with evaporation. Plant Cell Environ. 8:247-251.

Brewer, C.A., and W.K. Smith. 1997. Patterns of leaf surface wetness for montane and subalpine plants. Plant Cell Environ. 20:1-11.

Brewer, C.A., W.K. Smith, and T.C. Vogelmann. 1991. Functional interaction between leaf trichomes, leaf wettability, and the optical properties of water droplets. Plant Cell Environ. 14:955-962.

Bunnenburg, C., and W. Kuhn. 1977. Applications of beta-ray and electronic leaf wetness sensors in a dew chamber. Int. J. Biometeorol. 31:83-90.

Burkhardt, J., and R. Eiden. 1994. Thin water films on coniferous needles. Atmos. Environ. 28:2001-2017.

Butler, D.R. 1980. Dew and thermal lag: Measurements and estimates of wetness duration on cocoa pods. Q.J.R. Meteorol. Soc. 106:539-550.

Butt, D.J., and C.V. McGlinn. 1989. Tests of surface wetness sensors used with electronic diseasewarning instruments. p. 57-64. In C. Gessler et al. (ed.) Integrated control of pome fruit diseases. Proc. 2nd. Workshop Vol. II., Brissago, Switzerland, 30 Oct.-4 Nov. 1988. IOBC/WPRS Bull. 1989/XII/6. IOBC/WPRS, Darmstadt, Germany.

Campbell, C.L, and L.V. Madden. 1990. Introduction to plant disease epidemiology. John Wiley \& Sons, New York.

Chtioui, Y., L. Francl, and S. Panigrahi. 1999. Moisture prediction from simple micrometeorological data. Phytopathology 89:668-672.

Crisp, D.J. 1963. Waterproofing mechanisms in animals and plants. p. 416-481. In J.L. Molliet (ed.) Waterproofing and water repellency. Elsevier, Amsterdam.

Crowe, M.J., S.M. Coakley, and R.G. Emge. 1978. Forecasting dew duration at Pendleton, Oregon, using simple weather observations. J. Appl. Meteorol. 17:1482-1487.

Davis, D.R., and J.E. Hughes. 1970. A new approach to recording the wetting parameter by use of electrical resistance sensors. Plant Dis. Rep. 54:474-479.

Deshpande, R.Y., K.G. Hubbard, D.P. Coyne, J.R. Steadman, and A.M. Pankhurst. 1995. Estimating leaf wetness in dry bean canopies as a prerequisite to evaluating white mold disease. Agron. J. 87:613-619.

Francl, L.J., and S. Panigrahi. 1997. Artificial neural network models of wheat leaf wetness. Agric. For. Meteorol. 88:57-65.

Fuchs, M., and C.B. Tanner. 1966. Infrared thermometry of vegetation. Agron. J. 58:597-601.

Galliani, G., and F. Screpanti. 1993. A model to estimate leaf-wetness duration using standard weather-station data. Int. J. Simulat. Model. 13:167-171.

Garratt, J.R., and M. Segal. 1988. On the contribution of atmospheric moisture to dew formation. Boundary-Layer Meteorol. 45:209-236.

Giesler, L.J., G.L. Horst, and G.Y. Yuen. 1996. A site-specific sensor for measuring leaf wetness duration within turfgrass canopies. Agric. For. Meteorol. 81:145-156.

Gillespie, T.J., and A. Barr. 1984. Adaption of a dew estimation scheme to a new crop and site. Agric. For. Meteorol. 25:283-296.

Gillespie, T.J., B. Brisco, R.J. Brown, and G.J. Sofko. 1990. Radar detection of a dew event in wheat. Remote Sens. Environ. 33:151-156.

Gillespie, T.J., and R.X. Duan. 1987. A comparison of cylindrical and flat plate sensors. Agric. For. Meteorol. 40:61-70.

Gillespie, T.J., and G.E. Kidd. 1978. Sensing duration of leaf moisture retention using electrical impedance grids. Can. J. Plant. Sci. 58:179-187.

Gleason, M.L., S.K. Parker, R.E. Pitbaldo, R.X. Latin, D. Speranzini, R.V.Hazzard, M.J. Maletta, W.P. Cowgill, and D.L. Biederstedt. 1997. Validation of a commercial system for remote estimation of wetness duration. Plant Dis. 81:825-829.

Gleason, M.L., S.E. Taylor, T.M. Loughin, and K.J. Koehler. 1994. Development and validation of an empirical model to estimate the duration of dew periods. Plant Dis. 78:1011-1016.

Griffieon, H., J.G. Kornet, and K. Schurer. 1992. An optical leaf wetness sensor. Acta Hort. 304:127-135.

Häckel, H. 1980. New aspects on an electrical method for measuring the wetness duration immediately on leaves. (In German, with English abstract.) Agric. Meteorol. 22:113-119. 
Hall, F.R., R.A. Downer, J.A. Cooper, T.A. Ebert, and D.C. Ferree 1997. Changes in spray retention by apple leaves during the growing season. HortScience 32:858-860.

Hirst, J.M. 1954. A method for recording the formation and persistence of water deposits on plant shoots. Q.J.R. Meteorol. Soc. 80:227-231.

Holtzer, T.O., J.M. Norman, T.M. Perring, J.S. Berry, and J.C. Heintz. 1988. Effects of microenvironement on the dynamics of spider-mite populations. Environ. Appl. Acarology 4:247-264.

Hoppmann, D., and K.P. Wittich. 1997. Epidemiology-related modelling of the leaf wetness duration as an alternative to measurements, taking Plasmopara viticola as an example. Z. Pflanzenk. Pflanzen. 104:533-544.

Hoppmann, D., and K.P. Wittich. 2000. The use of leaf wetness duration in the routine agrometeorological advisory service of the Deutscher Wetterdienst. p. 81-83. In Proc. 3rd Int. Workshop Grapevine Downy and Powdery Mildew. 21-28 Mar. 1998. South Australian Research and Development Institute, Adelaide, Australia.

Huband, N.D.S., and D.R. Butler. 1984. A comparison of wetness sensors for use with computer or microprocessor systems designed for disease forecasting. p. 633-638. In Proc. British Crop Protection Conf. Pests and Diseases. BCPC, Alton, England.

Huber, L. 1988. Modéle de simulation de la durée d'humectation des feuilles au champ après une pluie. Cas d'un couvert homogène. (In French, with English abstract.) Agromonie 8:675-684.

Huber, L., D. Flura, B. Durand, and M. Clerjeau. 1991. Etude micrométéorologique de la durée d'humectation des grappes de vigne. (In French, with English abstract.) EPPO Bull. 21:441-449.

Huber, L., and T.J. Gillespie. 1992. Modeling leaf wetness in relation to plant disease epidemiology. Ann. Rev. Phytopath. 30:553-77.

Huber, L., and B. Itier. 1990. Leaf wetness in a field bean canopy. Agric. For. Meteorol. 51:281-291.

Hugues, R.N., and P. Brimblecombe. 1994. Dew and guttation: Formation and environmental significance. Agric. For. Meteorol. 67:173-190.

Huschke, R.E. 1959. Glossary of meteorology. Am. Meteorol. Soc., Boston MA.

Jacobs, A.F.G., W.A.J. van Pul, and R.M.M. El-Kilani. 1994. Dew formation and the drying process within a maize canopy. Boundary-Layer Meteorol. 69:367-378.

Jacobs, A.F.G., W.A.J. van Pul, and A. van Dijken. 1990. Similarity moisture dew profiles within a corn canopy. J. App. Meteorol. 29:1300-1306.

Jones, A.L. 1986. Role of wetting periods in predicting foliar disease. p. 87-100. In K.J. Leonard and W.E. Fry (ed.) Plant disease epidemiology. Vol. I. MacMillan Publ. Company, New York.

Jones, A.L., S.L. Lillevik, P.D. Fisher, and T.C. Stebbins. 1980. A microcomputer based instrument to predict apple scab infection periods. Plant Dis. 64:69-72.

Kelley, J.G.W., J.M. Russo, J.R. Eyton, and T.N. Carlson. 1988. Mesoscale forecasts generated from operational numerical weather-prediction model output. Bull. Am. Meteorol. Soc. 69:7-15.

Kim, K.S., S.E. Taylor, M.L. Gleason, and K.J. Koehler. 2002. Model to enhance site-specific estimation of leaf wetness duration. Plant Dis. 86:179-185.

Kuuseoks, E, H.O. Liechty, D.D. Reed, and J. Dong. 1997. Relating site-specific weather data to regional monitoring networks in the lake states. For. Sci. 43:447-452.

Lau, Y, M. Gleason, N. Zriba, E. Taylor, and P. Hinz. 1999. Effects of coating, angle, and compass orientation on performance of wetness sensors during dew periods. Plant Dis. 84:192-197.

Leclerc, M.Y., P.H. Schuepp, and G.W. Thurtell. 1986. Electrochemical simulation of mass transfer from isolated wet spots and droplets on realistic fluttering leaves. Boundary-Layer Meteorol. 34:399-410.

Leclerc, M.Y., G.W. Thurtell, and T.J. Gillespie. 1985. Laboratory simulation of evaporation of water droplets on artificial soybean leaves. Agric. For. Meteorol. 36:105-111.

Laurenson, M.R. 2002. A study on the development of a distributed computing framework for agricultural decision support systems. Ph.D. diss. Tsukuba Univ., Japan.

Lee, I.Y., and M.L. Welsely. 1989. Effects of surface wetness on the evolution and vertical transport of submicron particles. J. Appl. Meteorol. 28:176-184.

Lhomme, J., and F. Jimenez O. 1992. Estimating dew duration on banana and plantain leaves from standard meteorological observations. Agric. For. Meteorol. 62:263-274.

Linacre, E. 1992. Climate data and resources. Routledge, London.

Llorente, I., and E. Montesinos. 2002. Effect of relative humidity and interrupted wetness periods on brown spot severity of pear caused by Stemphylium vesicarium. Phytopathology 92:99-104.

Lomas, J. 1991. Sprinkler irrigation and plant disease under semi-arid conditions. EPPO Bull. 21:365-370.

Lomas, J., and Y. Shashoua. 1970. The performance of three types of leaf wetness recorders. Agric. Meteorol. 7:159-166. 
Louw, G., and M. Seely. 1982. Ecology of desert organisms. Longman, New York.

Madeira, A.C., T.J. Gillespie, and C.L. Duke. 2001. Effect of wetness on turfgrass canopy reflectance. Agric. For. Meteorol. 107:117-130.

Madeira, A.C., K.S. Kim, S. E. Taylor, and M. L. Gleason. 2002. A simple cloud-based energy balance model to estimate dew. Agric. For. Meteorol. 111:53-63.

Magarey, R.D. 1999. A theoretical standard for surface wetness estimation. Ph.D. diss. Cornell Univ., Ithaca, NY.

Magarey, R.D., J.M. Russo, and R.C. Seem, and D.M. Gadoury. (2004). Surface wetness duration under controlled environmental conditions. Agric. For. Meteorol. 128:111-122.

Magarey, R.D., R.C. Seem, J.M. Russo, J.W. Zack, K.T. Waight, J.W. Travis, and P.V. Oudemans. 2001. Site-specific weather information without on-site sensors. Plant Dis. 85:1216-1226.

Mahfouf, J., and B. Jacquemin. 1989. A study of rainfall interception using a land surface parameterization for mesoscale meteorological models. J. Appl. Meteorol. 28:1282-1302.

Manobianco, J., J.W. Zack, and G.E. Taylor. 1996. Workstation-based real-time mesoscale modeling designed for weather support to operations at the Kennedy Space Center and Cape Canaveral Air Station. Bull. Am. Meteorol. Soc. 77:653-672.

Miranda, R.A.C., D.D. Davies, and S.E. Cornell. 2000. A laboratory assessment of wetness sensors for leaf, fruit and trunk surfaces. Agric. For. Meteorol. 102:263-274.

Monteith, J.L. 1957. Dew. Q.J. Roy. Meteorol. Soc. 83:322-41.

Monteith, J.L., and D.R. Butler. 1979. Dew and thermal lag: A model for cocoa pods. Q.J.R. Meteorol. Soc. 105:207-215.

Monteith, J.L., and M.H. Unsworth. 1990. Principles of environmental physics. Edward Arnold, New York.

Mowrer, H.T. 1999. Accuracy (re)assurance: Selling uncertainty assessment to the uncertain. p. 3-10. In K. Lowell and A. Jaton (ed.) Spatial accuracy assessment: Land information uncertainty in natural resources. APS Press, St. Paul, MN.

Muller, W. 1992. Suitability of medium-range predictions of classical meteorological parameters and of the duration of leaf wetness for biometeorological forecasts. Int. J. Biometeorol. 36:45-50.

Noilhan, J., and S. Planton. 1989. A simple parameterization of land surface processes for meteorological models. Mon. Weath. Rev. 117:536-549.

Norman, J.M., and G. Campbell. 1983. Application of a plant environment model to problems in the environment. Adv. Irrig. 2:155-188.

Nwanze, K.F., Y.V.R. Reddy, F.E. Nwilene, P. Soman, K.B. Laryea, and R. Jayachandran. 1996. Reduction of shoot fly damage in irrigated post-rainy season sorghum by manipulating irrigation. Ann. Appl. Biol. 129:391-403.

Payen, D. 1983. Modélisation de l'épidemiologie de Sclerotinia sclerotium sur tournesol. (In French, with English abstract.) EPPO Bull. 13:277-281.

Pedro, M.J., and T.J. Gillespie. 1982a. Estimating dew duration: I. Utilizing micrometeorological data. Agric. Meteorol. 25:283-296.

Pedro, M.J., and T.J. Gillespie. 1982b. Estimating dew duration: II. Utilizing standard weather station data. Agric. Meteorol. 25:297-310.

Penman, H.L. 1948. Natural evaporation from open water, bare soil and grass. Proc. R. Soc. A 193:120-145.

Penrose, L.J., and H.J. Nicol. 1996. Aspects of microclimate variation within apple tree canopies and between sites in relation to potential Venturia inequalis infection. New Zeal. J. Crop Hort. Sci. 24:259-266.

Potratz, K.J., M.L. Gleason, M.L. Hockmuth, S.K. Parker, and G.A. Pearston. 1994. Testing the accuracy and precision of wetness sensors in a tomato field and turfgrass. J. Iowa Acad. Sci. 101:56-60.

Ross, J. 1975. Radiative transfer in plant communities. p. 13-55. In Vegetation and the atmosphere. Vol 1. Principles. Academic Press, London.

Rotem, J. 1988. Techniques of controlled-condition experiments. p. 19-31. In J. Kranz and J. Rotem. (ed.) Experimental techniques in plant pathology. Springer-Verlag, New York.

Royer, M.H., J.M. Russo, and J.G.W. Kelley. 1989. Plant disease prediction using a mesoscale weather forecasting technique. Plant Dis. 65:394-399.

Royle, D.J., and D.R. Butler. 1986. Epidemiological significance of liquid water in crop canopies and its role in disease forecasting. p. 139-156. In P.G. Ayres and L. Boddy (ed.) Water, fungi and plants. Cambridge Univ. Press, Cambridge, England.

Russo, J.M. 2000. Weather forecasting for IPM. p. 453-473. In G.G. Kennedy and T.B. Sutton (ed.) Emerging technologies for integrated pest management: concepts, research, and implementation. APS Press, St. Paul, MN. 
Russo, J.M., D. Bass, and A. Bardosy. 1993. Uncertainty analysis of simulated weather information. p. 11-15. In B. Bass (ed.) Weather generator project. Vol. I. BAHC Focus 4: BAHC Core Project Office. IGPP-ICSU, Institute for Meteorology, Free University, Berlin, Germany.

Sadler, E.J. 1996. Considerations for determining leaf wetness using infrared thermometry in humid regions. In Proc. 12th Conf. Biometeorol. Aerobiol. J1.3:6-7. Am. Meteorol. Soc., Boston.

Scherm, H., S.T. Koike, F.F. Laemmlen, and A.H.C. van Bruggen. 1995. Field evaluation of fungicide spray advisories against lettuce downy mildew Bremia lactucae based on measured or forecast morning leaf wetness. Plant Dis. 79:511-516.

Scherm, H., and A.H.C. van Bruggen. 1993. Sensitivity of simulated dew duration to meteorological variations in different climatic regions of California. Agric. For. Meteorol. 66:229-245.

Schuepp, P.H. 1989. Microstructure, density and wetness effects of dry deposition to foliage. Agric. For. Meteorol. 47:179-198.

Schurer, K., and A.F. van der Wal. 1972. An electronic leaf wetness recorder. Nether. J. Plant Path. 78:29-32.

Seem, R.C., R.D. Magarey, J.W. Zack, and J.M. Russo. 2000. Estimating disease risk at the whole plant level with general circulation models. Environ. Pollut. 108:389-395.

Seem, R.C., H.A. Magnus, and V. Hjonnevaag. 1991. High resolution weather information for plant protection. EPPO Bull. 21:355-364.

Seem, R.C., G. Rubin, and C.J. Becker. 1988. Duration of leaf wetting and drying periods in orchards. Phytopathology 78:1571 (Abstract).

Sellers, P.J., and J.G. Lockwood. 1981. A computer simulation model of the effects of the water balance of small catchments over long time periods. Q.J.R. Meteorol. Soc. 107:395-414.

Snedecor, G.W., and Cochran, W.G. 1989. Statistical methods. 8th ed. Iowa State Univ. Press, Ames.

Sutton, J.C., T.J. Gillespie, and P.D. Hildebrand. 1984. Monitoring weather factors in relation to plant disease. Plant Dis. 68:78-84.

Tanner, C.B., and M. Fuchs. 1968. Evaporation from unsaturated surfaces: A generalized combination method. J. Geophys. Res. 73:1299-1304.

Thompson, N.E. 1982. The duration of leaf wetness. Meteorol. Mag. 110:1-12.

Tuzet, A., A. Perrier, and A.K. Oulid Aissa. 1993. A prediction model for field drying of hay using a heat balance method. Agric. For. Meteorol. 65:63-89.

Vancauwenberghe, O., J. Short, E. Giehler, P. Bildstein, P. Ancey, and M. Gschwind. 1996. Microsensor for the preventive detection of water condensation: Operating principle and interface electronics. Sensor. Actuat. B-Phys. 53:304-308.

Vincelli, P.C., and J.W. Lorbeer 1988. Comparison of predictive systems for timing the initial fungicide application to control Botrytis leaf blight of onion. Plant Dis. 72:632-635.

Wallin, J.R. 1963. Dew, its significance and measurement in phytopathology. Phytopathology $53: 1210-1216$.

Wallin, J.R. 1967. Agrometeorological aspects of dew. Agric. Meteorol. 4:85-102.

Watanabe, T., and K. Mizutani. 1996. Model study on micrometeorological aspects of rainfall interception over an evergreen broad-leaved forest. Agric. For. Meteorol. 80:195-214.

Wei, Y.Q., B.J. Bailey, and B.C. Stenning. 1995. A wetness sensor for detecting condensation on tomato plants. J. Agric. Eng. Res. 61:197-204.

Weiss, A. 1990. Leaf wetness: Measurements and models. Remote Sens. Rev. 5:215-224.

Weiss, A., and A.F. Hagan. 1983. Further experiments on the measurements of leaf wetness. Agric. Meteorol. 29:207-212.

Weiss, A., and D.L. Lukens. 1981. Electronic circuit for detecting leaf wetness and comparison of two sensors. Plant Dis. 65:41-43.

Weiss, A., D.L. Lukens, J.M. Norman, and J.R. Steadman. 1989. Leaf wetness in dry beans under semi-arid conditions. Agric For. Meteorol. 48:149-162.

Weiss, A., D.L. Lukens, and J.R. Steadman. 1988. A sensor for the direct measurement of leaf wetness: Construction techniques and testing under controlled conditions. Agric. For. Meteorol. 43:241-249.

Weihong, L., and J. Goudriaan. 1991. Analysis of leaf wetness in the rice crop caused by dew formation: A simulation study. EPPO Bull. 21:551-559.

Weihong, L., and J. Goudriaan. 1999. Effects of altering water temperature on leaf wetness in paddy rice crops. Agric. For. Meteorol. 97:33-42.

Weihong, L., and J. Goudriaan. 2000. Dew formation on rice under varying durations of nocturnal radiative loss. Agric. For. Meteorol. 104:303-313.

Wigneron, J.P., J.C. Calvet, and Y. Kerr. 1996. Monitoring water interception by crop fields from passive microwave observations. Agric. For. Meteorol. 80:177-194. 
Wilks, D.S. 1995. Statistical methods in the atmospheric sciences. Academic Press, San Diego.

Wilks, D.S., and K.W. Shen. 1991. Threshold relative humidity duration forecasts for plant disease prediction. J. Appl. Meteorol. 30:463-477.

Wilson, T.B., W.L Bland, and J.M. Norman. 1999. Measurement and simulation of dew accumulation and drying in a potato canopy. Agric. For. Meteorol. 93:111-119.

Wittich, K.P. 1995. Some remarks on dew duration on top of an orchard. Agric. For. Meteorol. 72:167-180.

Yarwood, C.E. 1978. Water and the infection process. p. 141-173. In T.T. Kozlowski (ed.) Water deficits and plant growth. Volume V. Water and plant disease. Academic Press, New York.

Zhang, Y., and T.J. Gillespie. 1990. Estimating maximum droplet wetness duration from nearby weather station data. Agric. For. Meteorol. 51:148-158. 